(C) 2020 by the Arizona Board of Regents on behalf of the University of Arizona. This is an Open Access article, distributed under the terms of the Creative Commons Attribution licence (http://creativecommons. org/licenses/by/4.0/), which permits unrestricted re-use, distribution, and reproduction in any medium, provided the original work is properly cited.

\title{
WOOD FROM THE NETHERLANDS AROUND THE TIME OF THE SANTORINI ERUPTION DATED BY DENDROCHRONOLOGY AND RADIOCARBON
}

\author{
Margot Kuitems ${ }^{1} \cdot$ Johannes van der Plicht $^{1 *}{ }^{*}$ - Esther Jansma ${ }^{2,3}$ \\ ${ }^{1}$ Center for Isotope Research, Groningen University, Nijenborgh 6, 9747 AG Groningen, The Netherlands \\ ${ }^{2}$ Cultural Heritage Agency of the Netherlands, Amersfoort, The Netherlands \\ ${ }^{3}$ The Netherlands Centre for Dendrochronology/RING Foundation, Amersfoort, The Netherlands
}

\begin{abstract}
Eighteen new high-precision radiocarbon $\left({ }^{14} \mathrm{C}\right)$ dates obtained for dendrochronologically dated wood from Bodegraven, the Netherlands are reported. They are relevant for establishing the revised calibration curve around the time of the Bronze Age Santorini eruption. Most of our new data overlap within one sigma with IntCal13, but a few data points are slightly increased in ${ }^{14} \mathrm{C}$ age compared to IntCal13.
\end{abstract}

KEYWORDS: calibration, Santorini.

\section{INTRODUCTION}

The catastrophic Minoan eruption of Santorini (Thera) in the second millennium BCE provides a crucial chronological anchor for Bronze Age prehistory. The precise date of the eruption has been debated for decades (for a recent overview see Antiquity 2014). Radiocarbon $\left({ }^{14} \mathrm{C}\right.$ ) dates play a major role in this discussion. These need to be calibrated to derive historical dates. Obviously, historical inference largely depends on the exact shape of the calibration curve. Recently, a new single year calibration record became available, its content indicating that the curve needs to be revised (Pearson et al. 2018). This spawned major (re)dating efforts of dendrochronologically dated wood dating to the time of the Santorini eruption. Here, we present a short report on 18 such new dates from the Netherlands.

\section{METHODS AND RESULTS}

In 1996, four trees were found during infrastructural work by Holland Railconsult (now: Movares) in Bodegraven, the Netherlands. The approximate coordinates of the location are latitude 52.0823259, and longitude 4.7460844. The tree species is Quercus robur/petraea. The trees were analyzed and two of them were dated at the Netherlands Centre for Dendrochronology/RING Foundation in Amersfoort. One of the dated trees (coded BOF00041) has a growth pattern covering the time of the Santorini eruption. Hence, this wood has been selected presently for dating by ${ }^{14} \mathrm{C}$, for cross checking the calibration curve.

\section{Dendrochronology}

The tree sample BOF00041 contains a total of 186 rings. It does not contain sapwood, implying that at least a sapwood zone covering $26 \pm 8 \mathrm{yr}$ is lacking on the outside of the wood. The tree-rings were dated to 1737-1552 BCE (dataset developed by Hanraets and Jansma 1997, see Jansma et al. 2012). The reference chronologies used are from North Germany (Leuschner and Delorme 1988; Leuschner, unpublished data) and the Netherlands ('NLPre_ZH; Jansma 1995). In general, narrow rings in the bog oaks from the Netherlands correspond very well with these from North Germany. Examples have been published in Leuschner et al. (2003). The dendrochronological parameters are shown in Table 1.

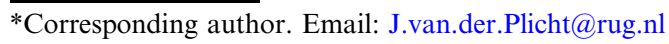


Table 1 Dendrochronological parameters for the Bodegraven bog oak BOF00041.

\begin{tabular}{lccc}
\hline Reference curve & $\% \mathrm{PV}$ & $\mathrm{t}$ & $\mathrm{P}$ \\
\hline North Germany & 63.5 & 6.29 & 0.0005 \\
NLPre_ZH & 62.7 & 5.84 & 0.001 \\
\hline
\end{tabular}

Table 2 Dendrochronological and radiocarbon dates for the Bodegraven tree. Listed are GrM-number, dendro-date (year BCE), number of analyzed tree rings, radiocarbon date (BP) and its uncertainty, and $\delta^{13} \mathrm{C}(\%)$ as determined by IRMS.

\begin{tabular}{lccccc}
\hline Lab reference & $\begin{array}{c}\text { Dendro-date } \\
\text { (yr BCE) }\end{array}$ & $\begin{array}{c}\mathrm{Nr} \text { of } \\
\text { tree rings }\end{array}$ & $\begin{array}{c}{ }^{14} \mathrm{C} \text { age } \\
(\mathrm{BP})\end{array}$ & $\begin{array}{c}\sigma \\
(\mathrm{BP})\end{array}$ & $\begin{array}{c}\delta^{13} \mathrm{C} \\
(\%)\end{array}$ \\
\hline GrM-12153 & 1565 & 10 & 3297 & 15 & -25.98 \\
GrM-12154 & 1575 & 10 & 3314 & 15 & -24.69 \\
GrM-12155 & 1585 & 10 & 3325 & 15 & -25.00 \\
GrM-12156 & 1595 & 10 & 3299 & 15 & -24.76 \\
GrM-12158 & 1605 & 10 & 3339 & 15 & -24.66 \\
GrM-12160 & 1615 & 10 & 3335 & 15 & -25.05 \\
GrM-12161 & 1625 & 10 & 3350 & 15 & -25.11 \\
GrM-12163 & 1635 & 10 & 3373 & 15 & -25.09 \\
GrM-12164 & 1645 & 10 & 3380 & 15 & -24.44 \\
GrM-12760 & 1612 & 1 & 3337 & 15 & -25.12 \\
GrM-12761 & 1618 & 1 & 3357 & 15 & -25.09 \\
GrM-12762 & 1635 & 1 & 3403 & 15 & -25.33 \\
GrM-12764 & 1643 & 1 & 3375 & 15 & -24.25 \\
GrM-12765 & 1647 & 1 & 3380 & 15 & -25.37 \\
GrM-12766 & 1650 & 1 & 3405 & 15 & -24.17 \\
GrM-12767 & 1655 & 1 & 3353 & 15 & -23.99 \\
GrM-12769 & 1657 & 1 & 3357 & 15 & -24.28 \\
GrM-12771 & 1660 & 1 & 3378 & 15 & -26.50 \\
\hline
\end{tabular}

The parameter $\% \mathrm{PV}$ is percentage of parallel variaton, also known as "Gleichlaufigkeit". It is the percentage of rings showing simultaneous increases and decreases of tree-ring width relative to the reference chronology (Jansma 1995). The parameter t is the result of a Student's t-test for the Pearson's cross-correlation coefficient between the tree-ring pattern and that of the reference chronology. The parameter $\mathrm{P}$ is the probability that the $\% \mathrm{PV}$ value is coincidental, expressed as a fraction of 1 .

\section{Radiocarbon}

The two series of tree rings were dated by AMS in Groningen. For ${ }^{14} \mathrm{C}$ dating we selected 9 decadal- and 9 single-year wood samples, as indicated in Table 2. All the samples were pretreated to $\alpha$-cellulose using the method of Groningen (Dee et al. 2020). In brief, the 
(a)

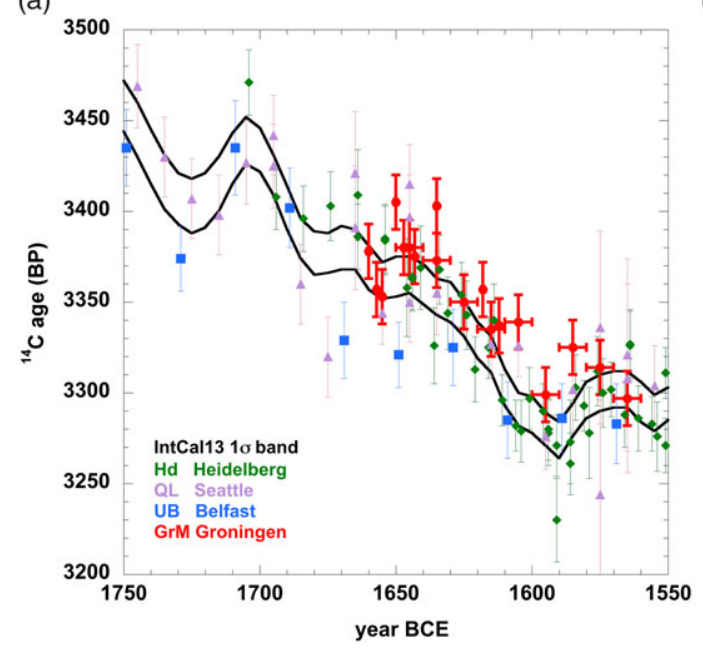

(b)

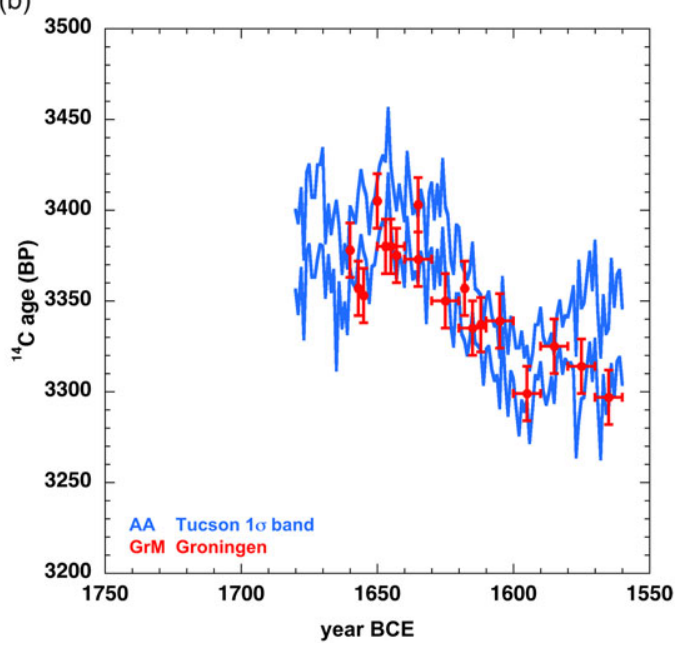

Figure 1 The Groningen (GrM) measurements for the Bodegraven tree, shown in red. (a) GrM dates shown together with the IntCal13 calibration curve (black) and the conventional dates (Hd, QL and UB) the latter is determined from. (b) GrM dates shown together the AA dates (Pearson et al. 2018). (Please see electronic version for color figures.)

tree-rings (early- and late-wood not separated) were cut into much smaller fragments with a scalpel. Aliquots of $\sim 50 \mathrm{mg}$ (or all available) of the fragments were weighed into 12-mL test tubes. Then, the samples were exposed to a strong acid $\left(\mathrm{HCl}, 1.5 \mathrm{M}, 80^{\circ} \mathrm{C}, 20 \mathrm{~min}\right)$, strong base $(\mathrm{NaOH}, 17.5 \% \mathrm{w} / \mathrm{vol}, 60 \mathrm{~min}, \mathrm{RT})$, acid $\left(\mathrm{HCl}, 1.5 \mathrm{M}, 80^{\circ} \mathrm{C}, 20 \mathrm{~min}\right)$, and finally to strong oxidation $\left(\mathrm{NaClO}_{2}, 1.5 \% \mathrm{w} / \mathrm{vol}\right.$ in $\mathrm{HCl}, 0.06 \mathrm{M}, 16 \mathrm{hr}, 80^{\circ} \mathrm{C}$ ), with rinses using deionized, ultrapure water after each chemical step.

The alpha cellulose was combusted to $\mathrm{CO}_{2}$ by an elemental analyzer, connected to a stable isotope mass spectrometer (EA/IRMS, Elementar Vario Isotope Cube TM/Isoprime $^{\mathrm{TM}}$ $100^{\mathrm{TM}}$ ). The latter provides the stable isotope ratio $\delta^{13} \mathrm{C}$ (in $\%$, relative to the VPDB standard; Mook 2006). Part of the $\mathrm{CO}_{2}$ is transferred into graphite, by a reaction with $\mathrm{H}_{2}$ gas at a temperature of about $600^{\circ} \mathrm{C}$, using $\mathrm{Fe}$ powder as catalyst (Aerts-Bijma et al. 2001). The graphite was pressed into target holders for the ion source of the AMS. The AMS is a MICADAS-17 (IonPlus ${ }^{\circledR}$ ) (Mini Carbon Dating System; Synal et al. 2007) manufactured by IonPlus, installed in 2017. The present Groningen laboratory code is GrM.

The results are shown in Table 2. Listed are the GrM-number, the dendrochronological date in $\mathrm{BCE}$, the ring width, the radiocarbon date in $\mathrm{BP}$, its uncertainty $(1 \sigma)$, and the $\delta^{13} \mathrm{C}$ value (in \%0) as determined by the IRMS.

The uncertainty of the latter is $0.15 \%$ o $(1 \sigma)$. These $\delta^{13} \mathrm{C}$ values are all consistent with those of the AMS.

The radiocarbon dates are reported by convention (van der Plicht and Hogg 2006), using the oxalic acid reference, the conventional half-life and isotopic fractionation correction using the 
$\delta^{13} \mathrm{C}$ measured by the AMS. The uncertainties of the ${ }^{14} \mathrm{C}$ dates are based on counting statistics and includes an estimate for internal laboratory error.

\section{DISCUSSION AND CONCLUSION}

The ${ }^{14} \mathrm{C}$ dates (Table 2) of the selected samples from bog oak BOF00041 are shown in Figure 1a. Also shown is the relevant part of the calibration curve IntCall3 (Reimer et al. 2013). Also, the individual data used for construction of the curve are shown. These are high-precision radiometric dates from the laboratories Heidelberg (Hd), Belfast (UB) and Seattle $(\mathrm{QL})$. The error bars plotted are all $1 \sigma$. For the IntCal curve, the $1-\sigma$ envelope is shown in Figure 1a.

As visible in Figure 1a, the GrM-dates are fairly consistent with the IntCal13 curve. Indeed, most of our new data overlap within $1 \sigma$ with IntCal13 but a few data points are slightly increased compared to IntCal13. Therefore, our data confirm that the calibration curve needs to be raised for the time range around $1600 \mathrm{BCE}$, but not as dramatically as suggested by Pearson et al. (2018), see Figure 1b. Our data will be implemented in the new calibration curve IntCal20 (Reimer et al. 2020 in this issue), together with denser (long single-year series) datasets which became available as well (this issue). Based on all available new data, the implications of calibration for the Santorini eruption will be discussed in more detail elsewhere (van der Plicht et al. 2020 in this issue).

\section{ACKNOWLEDGMENTS}

This work was supported by an European Research Council grant (ECHOES, nr. 714679).

\section{REFERENCES}

Aerts-Bijma AT, van der Plicht J, Meijer HAJ. 2001. Automatic AMS sample combustion and $\mathrm{CO}_{2}$ collection. Radiocarbon 43:293-298.

Antiquity. 2014. Debate feature: Bronze Age catastrophe and modern controversy: dating the Santorini eruption. Antiquity 88:267-291.

Dee MW, Palstra SWL, Aerts-Bijma ATh, Bleeker MO, de Bruijn S, Ghebru F, Jansen HG, Kuitems M, Paul D, Richie R, et al. 2020. Radiocarbon dating at Groningen: New and updated chemical pretreatment procedures. Radiocarbon 62(1): 63-74. doi: 10.1017/RDC.2019.101.

Jansma E. 1995. RemembeRINGs. The development and application of local and regional tree- ring chronologies of oak for the purposes of archaeological and historical research in the Netherlands [dissertation]. Amsterdam University. Nederlandse Archeologische Rapporten (NAR) 19.

Jansma E, van Lanen RJ, Brewer PW, Kramer R. 2012. The DCCD: A digital data infrastructure for tree-ring research. Dendrochronologia 30:249-251. doi: 10. 1016/j.dendro.2011.12.002. P:1997013, sample ID:1997013:BOF:0004:1, dataset developed in 1997 by Hanraets W, Jansma E (Netherlands Centre for Dendrochronology/RING Foundation).
Leuschner HH, Delorme A. 1988. Tree-ring work in Gottingen: absolute oak chronologies back to 6255 BC. In: Hackens T, Munaur AV, Tills C, editors. Wood and Archaeology. Pact 22: 123-132.

Leuschner HH, Sass-Klaassen U, Jansma E, Baillie MGL, Spurk M. 2003. Population dynamics and long-term growth depressions in European bog oaks as indicators of climate changes in the Holocene. Schriften des Forschungszentrums Jülich, Reihe Umwelt 33:13-19.

Mook WG. 2006. Introduction to isotope hydrology. London: Taylor and Francis. ISBN 0415381975.

Pearson CL, Brewer PW, Brown D, Heaton TJ, Hodgins GWL, Jull AJT, Lange T, Salzer MW. 2018. Annual radiocarbon record indicates 16th century BCE date for the Thera eruption. Science Advances 4: eaar8241. doi: 10.1126/ sciadv.aar8241.

Reimer PJ, Bard E, Bayliss A, Beck JW, Blackwell PG, Bronk Ramsey C, Buck CE, Cheng H, Edwards RL, Friedrich M, et al. 2013. IntCal13 and Marine13 radiocarbon age calibration curves $0-50,000$ years cal BP. Radiocarbon 55:1869-87. 
Reimer PJ, Austin WEN, Bard E, Bayliss A, Blackwell P, Bronk Ramsey C, Butzin M, Edwards L, Friedrich M, Grootes PM, et al. 2020. The IntCal20 Northern Hemisphere radiocarbon calibration curve (0-55 cal kBP). Radiocarbon 62. This issue.

Synal HA, Stocker M, Suter M. 2007. MICADAS: a new compact radiocarbon AMS system. Nuclear
Instruments and Methods in Physics Research B 259:7-13.

van der Plicht J, Hogg A. 2006. A note on reporting radiocarbon. Quaternary Geochronology 1:237-240. van der Plicht J, Bronk Ramsey C, Heaton TJ, Scott EM, Talamo S. 2020. Recent developments in calibration for archaeological and environmental samples. Radiocarbon 62. This issue. 